\title{
RESISTÊNCIA À COMPRESSÃO E REMOÇÃO DE FOLHAS DA CANA-DE-AÇÚCAR VISANDO À COLHEITA MECÂNICA
}

\author{
PAUlO S. G. MAGALHÃES ${ }^{1}$, OSCAR A. BRAUNBECK ${ }^{2}$, NATASHA B. PAGNANO ${ }^{3}$
}

RESUMO: A cultura de cana-de-açúcar ocupa um papel importante na economia brasileira, sendo sua colheita ainda em grande parte realizada manualmente, pelo método tradicional de colheita de cana-deaçúcar inteira. As colhedoras existentes no mercado adotaram uma tecnologia de picar a cana-deaçúcar em rebolos de 200 a $300 \mathrm{~mm}$, para permitir sua transferência para o veículo de transporte que acompanha a colhedora, contradizendo o método tradicional de colheita. Para viabilizar a colheita mecânica de cana-de-açúcar inteira, uma das barreiras tecnológicas a ser vencida é a remoção da palha mecanicamente. Projetar um mecanismo que realize essa operação depende diretamente do conhecimento de propriedades mecânicas da cana-de-açúcar. Este trabalho teve por objetivo avaliar a resistência do colmo de cana-de-açúcar à compressão e determinar as forças necessárias para separar a folha do colmo. Ensaios de compressão foram realizados utilizando-se da máquina universal de ensaios. Para o ensaio de remoção de palha por atrito, um dispositivo especial foi projetado e construído de modo a permitir a determinação de esforços de tração e força normal. Os resultados mostram que a cana resiste a uma força de compressão na faixa de 4,9 MPa e que com uma pressão normal média de $0,8 \mathrm{MPa}$, que corresponde a uma força de fricção de $315 \mathrm{~N}$, a folha é removida, independentemente de sua posição no internódio.

PALAVRAS-CHAVE: propriedades mecânicas, Saccharum officinarum, cana crua.

\section{RESISTANCE TO COMPRESSION AND LEAVES REMOVAL OF SUGARCANE FOR MECHANICAL HARVESTING}

SUMMARY: Sugarcane holds an important place in the Brazilian economy. Grate part of the sugarcane harvested still accomplished largely manually. Sugarcane harvesters available in Brazil use the technology to chop the cane into 200 to $300 \mathrm{~mm}$ billets to allow on the go cane transferring to transport, contradicting the traditional method of whole stalk sugarcane harvesting system. In order to make whole stalk mechanical harvesting system possible, one of the barriers to be expired is the mechanical removal of the straw. The design of a mechanism that accomplishes this operation depends directly on the knowledge of the mechanical properties of the sugarcane related to its resistance to compression and the forces necessary to remove the leaves from the stalk. Compression tests were conducted using the universal testing machine. For leaves removal test by friction, a special apparatus was designed to allow the registration of the normal and traction force. The sugarcane stalk can resist up to $4.9 \mathrm{MPa}$. With a normal pressure of $0.8 \mathrm{MPa}$, which correspond to a friction force of $315 \mathrm{~N}$, it is possible to remove the leaves, independent of its location in the sugarcane stalk.

KEYWORDS: mechanical properties, Saccharum officinarum, green cane.

\footnotetext{
${ }^{1}$ Eng. Agrícola, Prof. Titular, Faculdade de Engenharia Agrícola, UNICAMP, Caixa Postal 6011, 13081-970, Campinas - SP, Fone: (0XX19) 3788.1053, e-mail: paulo@agr.unicamp.br

${ }^{2}$ Eng. Industrial, Prof. Adjunto, FEAGRI-UNICAMP, Campinas - SP.

${ }^{3}$ Aluna de Doutorado, FEAGRI/UNICAMP, Campinas - SP.

Recebido pelo Conselho Editorial em: 20-02-2002

Aprovado pelo Conselho Editorial em: 01-12-2003
} 


\section{INTRODUÇÃO}

Desde 1968 a indústria sucroalcooleira brasileira tem mostrado o interesse em colher cana inteira crua como mostra a patente 203.875 (1968) - despalhar sem queimar. O referido equipamento é constituído, basicamente, de uma estrutura, de um motor hidráulico, de uma serra circular, de um cilindro hidráulico e rotores aos quais são acoplados bastões ou chicotes de material flexível.

CLAYTON (1971), em um estudo desenvolvido na Flórida - EUA, menciona a prática de limpeza de cana picada, não queimada, separando os rebolos das pontas e folhas. Os mecanismos denominados "snappers" consistem de uma mesa de cilindros giratórios justapostos, destinados a destacar as palhas e pontas. A pequena dimensão desses cilindros não permite que os rebolos de cana sejam esmagados. $\mathrm{O}$ autor estudou diversos tipos de superfícies para os cilindros, as quais, muitas vezes, se apresentam em forma de garras. O referido trabalho discute, também, o fluxo de cana que alimenta o mecanismo, a qualidade de limpeza, bem como o desgaste dos cilindros.

MIYABE \& ABE (1976) realizaram testes com as forças necessárias para remover as folhas da cana-de-açúcar, utilizando máquina universal de ensaios e observaram que a força de tração para remover a folha varia com a posição no caule e com a direção de aplicação. A força média na oitava folha foi de $63,3 \mathrm{~N}$ folha ${ }^{-1}$ com ângulo de tração de $45^{\circ}$ e de $36 \mathrm{~N}$ folha ${ }^{-1}$ com ângulo de $135^{\circ}$. Os autores concluíram que, para remover as folhas da cana, o mecanismo deve ser composto de mais de uma força e não apenas a de tração.

Para verificar a resistência do caule à penetração, flexão, corte e esmagamento, MIYABE \& ABE (1979) fizeram ensaios e concluíram que a resistência à penetração varia com a localização do nó, tendendo a ser mais resistente na parte inferior do caule e na planta com mais idade. Concluíram, ainda, que a resistência à flexão e à rigidez aumenta do topo para a base e também com a idade da cana; e a resistência ao esmagamento aumenta com a idade da cana e do topo para a base.

MIYABE et al. (1979) realizaram ensaios de impacto verificando que a energia de impacto varia de acordo com a localização dos nós, aumentando do topo para a raiz. Os resultados mostram que o tecido interno do colmo é mais macio e mais elástico nos segmentos superiores da cana. De posse desses resultados, ABE et al. (1979) desenvolveram um sistema para a remoção das folhas da cana-deaçúcar, testando três tipos de mecanismos diferentes:

1. Sistema de corte com friç̧ão forçada (lâminas cilíndricas): nesse sistema, as folhas são cortadas e arrancadas do colmo pela ação de lâminas cilíndricas. O desempenho desse equipamento foi de 77,3 a $90,1 \%$ de remoção das folhas com $0 \%$ de danos à cana e com rendimento de 150 a $313 \mathrm{~kg}$ por homem-hora.

2. Sistema de fricção forçada: consiste de rolos feitos com arame de aço, corda-piano e correias em $\mathrm{V}$ que removiam as folhas. O desempenho foi de 76,6 a $89,8 \%$ com $1,1 \%$ de dano à cana e 156 a $190 \mathrm{~kg}$ por homem-hora de rendimento. Esse sistema apresentou algumas deficiências, embora um dano visível não fosse observado, as marcas de atrito eram bem visíveis, sendo 1 a $2 \mathrm{~mm}$ do material da casca removido após a ação dos rolos.

3. Sistema de impacto - fricção: nesse sistema, cordas flexíveis presas a rolos rotativos que proporcionam uma grande força de impacto pela força centrífuga na cana-de-açúcar, promovem a remoção das folhas. O desempenho ficou na faixa de 90,3 a $91,3 \%$ com 0,6 a 1,4\% de danos e um rendimento de 162 a $178 \mathrm{~kg}$ por homem-hora. Embora nesse sistema exista um pequeno dano à cana, a porcentagem de limpeza foi mais alta e a potência requerida menor que nos anteriores.

Os vários parâmetros envolvidos na retirada da palha da cana-de-açúcar foram estudados por SRIVASTAVA (1987) com a ajuda de análise dimensional. Uma equação geral para avaliar a força requerida para a remoção da palha ou da folha foi desenvolvida. 
SRIVASTAVA \& SINGH (1990) discutiram os esforços para estabilizar o mecanismo apropriado para retirar a palha da cana inteira. Uma unidade estacionária remove as folhas secas e verdes da cana. A capacidade da máquina é limitada pela taxa de alimentação manual da cana. A capacidade de retirar a palha foi maior que $1 \mathrm{t} \mathrm{h}^{-1} \mathrm{e}$ o peso da máquina era de aproximadamente $350 \mathrm{kgf}$.

SHUKLA et al. (1991) desenvolveram e testaram um sistema de rolos para limpar cana-deaçúcar. O equipamento separa o topo da cana madura, quebrando-o e removendo as folhas secas e verdes. O sistema de limpeza consiste de um tubo de alimentação, um cilindro, um rolo inferior, um rolo lateral, um rolo cortador e um ventilador montados sobre uma plataforma estacionária. É acionado por um motor diesel de $5,9 \mathrm{~kW}$. O equipamento foi testado para diferentes variedades de cana e para diferentes velocidades de rotação dos rolos. O melhor resultado, 0,87 a $6,38 \%$ de palha deixados na cana após a passagem pelo equipamento, foi obtido para a rotação de $300 \mathrm{rpm}$ com um ângulo de $25^{\circ}$ entre o cilindro e o tubo de alimentação.

A cultura de cana-de-açúcar ocupa um papel de destaque no agronegócio brasileiro, produzindo açúcar e álcool combustível, além de inúmeros outros produtos de relevância para a economia nacional. O País é o maior produtor mundial com uma área plantada de 5,4 milhões de hectares, situando-se 2,6 milhões de hectares no Estado de São Paulo (IEA, 2002). Apesar do rápido crescimento da colheita mecanizada, observado nos últimos anos, a colheita de cana-de-açúcar ainda é, em grande parte, realizada manualmente; nesse sistema, a cana é colhida inteira e posteriormente carregada e transportada para a usina (MAGALHÃES \& BRAUNBECK, 1998). Na colheita mecanizada, as colhedoras existentes no mercado cortam a cana-de-açúcar em pedaços de 200 a $300 \mathrm{~mm}$ de comprimento, descarregando direto em um caminhão ou carreta que acompanha lateralmente a colhedora; esse método tem obrigado a indústria a investir elevadas somas na substituição do sistema, tanto em transporte como na recepção da matéria-prima na usina.

Observa-se, também, que a colheita da cana-de-açúcar crua tem se expandido principalmente no Estado de São Paulo devido à legislação vigente ${ }^{4}$, que dispõe sobre a eliminação gradativa da queima da palha da cana-de-açúcar e dá providências correlatas, a qual surge da premente necessidade de proteger o meio ambiente. Hoje, com a valorização do bagaço de cana-de-açúcar, por meio da política de compra do excedente de energia elétrica produzida pelas usinas de açúcar e álcool, e sua utilização para outros fins mais nobres (CORTEZ et al., 1992, MACEDO, 2002), as usinas estão atentas para a possibilidade de utilizar palha de cana-de-açúcar para complementar o bagaço nas caldeiras.

Aproximadamente $90 \%$ das usinas do Brasil estão equipadas para operar com cana-de-açúcar inteira, mas não existem equipamentos comerciais para sua colheita mecanizada, apesar das claras vantagens desse tipo de colheita. A cana inteira sofre menos deterioração e, conseqüentemente, permite maior tempo de estocagem e, se no carregamento mecânico, for utilizado rastelo rotativo, a porcentagem de impurezas minerais presente é menor que na cana-de-açúcar picada. Apresenta ainda uma importante vantagem sobre a colheita de cana-de-açúcar picada, que é a total independência entre o sistema de colheita e transporte, permitindo uma eficiência maior de ambos os sistemas, tendo como conseqüência uma redução de custo operacional e de capital (menor número de caminhões utilizados na colheita).

Entretanto, a colheita mecanizada de cana-de-açúcar inteira tem problemas operacionais que dificultam sua utilização em cana não queimada. A presença de folhas e ponteiras na moenda apresenta vários problemas: as ponteiras têm baixo teor de sacarose, e seu suco de baixa pureza e alto grau de não-açúcares afeta o processo; as folhas removem a sacarose do suco, aumentam a quantidade de fibra e ajudam a promover o desgaste dos rolos da moenda.

\footnotetext{
${ }^{4}$ Lei Estadual no. 11.241, de 19 de setembro de 2002, Diário oficial - Estado de São Paulo, volume 112, no. 180, São Paulo.
} 
Dessa forma, assim como na colheita de cana picada, também na colheita de cana inteira, as folhas e ponteiras devem ser separadas do colmo para viabilizar o método. A remoção da palha mecanicamente é uma das barreiras tecnológicas a ser vencida e o projeto de um mecanismo que realize essa operação, depende do conhecimento das propriedades mecânicas da cana-de-açúcar.

O objetivo deste trabalho foi determinar propriedades da cana-de-açúcar com relação às forças necessárias para a remoção da palha por atrito e a resistência do colmo a tensões de compressão, a fim de obter dados para o dimensionamento de um dispositivo mecânico para a remoção da palha, visando à colheita mecânica da cana-de-açúcar. $O$ levantamento desses dados foi realizado para cinco variedades de cana-de-açúcar, em função do período de colheita e das diferentes características de cada variedade.

\section{MATERIAL E MÉTODOS}

Este trabalho foi conduzido no Laboratório de Propriedades Físicas e Mecânicas da Faculdade de Engenharia Agrícola da UNICAMP, durante o ano de 1994. Durante o estudo, foram testadas cinco variedades de cana-de-açúcar, representativas na época pela sua abrangência em área plantada no Estado de São Paulo, segundo informações do Censo de Variedades da Copersucar e com características diferentes em relação à facilidade de despalhe.

RB765418: variedade precoce de difícil despalhe;

RB72454: variedade mais plantada no Estado de São Paulo;

SP711406: variedade de fácil despalhe;

SP791011: variedade mais plantada em áreas de colheita mecanizada, e

SP701143: variedade com alto teor de fibra.

As amostras das canas foram fornecidas pela Usina Éster, situada no município de Cosmópolis SP, utilizando-se de cana de primeiro ou segundo corte, tendo sido colhida uma semana antes da realização de colheita pela usina.

Neste trabalho, optou-se pela realização de estudo observacional que, segundo BROOK \& ARNOLD (1985), ocorre quando indivíduos de uma amostra não são designados aos grupos por processo aleatório, mas classificados nos respectivos grupos por serem portadores de determinada característica. Nesses estudos, os efeitos dos tratamentos confundem-se com os efeitos de fatores que levaram o indivíduo a pertencer a um determinado grupo (HILL, 1977, citado por SOUSA \& NÄÄS, 2003). Conseqüentemente, a discussão dos efeitos de um tratamento, com base num estudo observacional, exige mais senso crítico do que a discussão dos efeitos de um tratamento estudado por meio de um experimento planejado (SOUSA \& NÄÄS, 2003).

Para a determinação da resistência à compressão máxima, foi utilizada a máquina universal de ensaios OTAWA, equipada com uma célula de carga de compressão de $1000 \mathrm{~N}$ de fundo de escala, com erro máximo de $1 \%$, fabricada pela Interface. Foi aplicada uma força radial de compressão à canade-açúcar, apoiada em prato plano, por meio de uma talisca de $0,0635 \mathrm{~m}$ de espessura, a uma velocidade constante de $2 \mathrm{~m} \mathrm{~s}^{-1}$.

Para a determinação da força de fricção necessária para a remoção da palha da cana-de-açúcar, foi projetado um dispositivo que permite aplicar uma força normal e uma força de tração e registrar esses esforços simultaneamente (Figura 1). Nesse dispositivo, foram utilizadas duas células de carga, uma de $500 \mathrm{~N}$ de fundo de escala (força normal) e outra de $1000 \mathrm{~N}$ de fundo de escala (força de tração), ambas com erro máximo de $1 \%$. 
Os sinais analógicos provenientes das células de carga, após passarem por um condicionador de sinais analógico marca Kyowa DPM-6G, utilizando uma placa de conversão analógico - digital Lynx, na taxa de aquisição de dados de $100 \mathrm{~Hz}$, foram armazenados em um computador tipo IBM 386. Os dados dos arquivos de saída foram analisados utilizando-se do programa AQDADOS, desenvolvido pela Lynx.

Para cada variedade de cana-de-açúcar, foram avaliados 30 colmos. Os ensaios foram feitos em diferentes posições ao longo do colmo, nas regiões basal, mediana e apical para que se pudesse avaliar a variação dos esforços necessários para remover a palha e comprimir a cana.

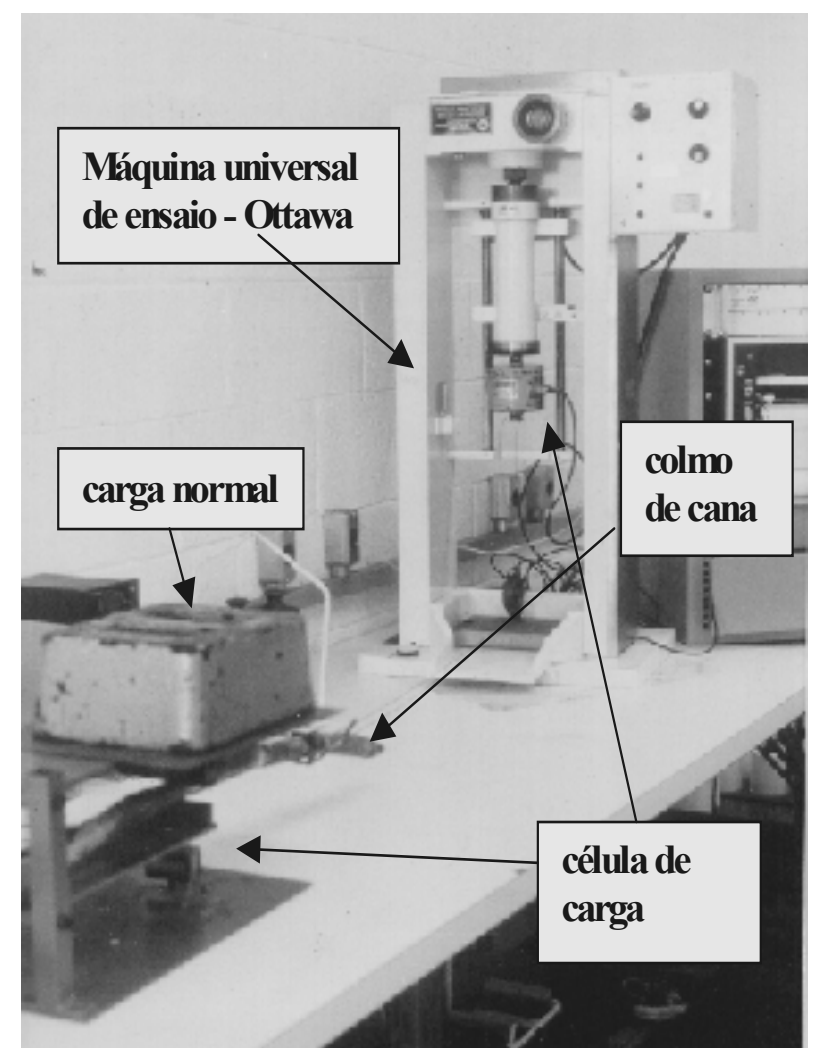

FIGURA 1. Dispositivo projetado para medir a força de tração necessária para a remoção da folha de cana-de-açúcar do colmo por atrito e máquina universal de ensaios.

\section{RESULTADOS E DISCUSSÃO}

Para as cinco variedades testadas, a pressão necessária para romper a cana apresentou um valor médio de 4,9 $\mathrm{MPa}$. Entre as variedades ou entre as diferentes posições dos colmos, a força de tração não apresentou diferenças significativas com $95 \%$ de confiança, quando realizamos uma análise comparativa das médias das forças necessárias para a remoção das folhas pela análise de variância (ANOVA). No entanto, uma análise individual de cada ensaio permitiu verificar uma tendência de o internódio basal ser mais resistente que o internódio perto do ponteiro (Tabela 1). O ponto de rompimento da estrutura da cana-de-açúcar foi determinado a partir dos gráficos de força de compressão versus deslocamento do cabeçote da máquina universal de ensaio. Na Figura 2, apresentase um exemplo desse ensaio. Nessa figura, pode-se observar que o colmo suporta, no início do processo, uma carga crescente até um valor máximo, nitidamente o ponto de ruptura da estrutura da cana-de-açúcar (nesse exemplo 5,5 s depois de iniciado o ensaio); a partir desse ponto, a carga 
suportada decresce, inicialmente a uma taxa maior e à medida que as fibras vão se acomodando, a taxas menores .

TABELA 1. Força média de compressão (N) suportada pela cana-de-açúcar.

\begin{tabular}{ccccc}
\hline \multirow{2}{*}{ Variedades } & \multicolumn{4}{c}{ Posição do Internódio } \\
\cline { 2 - 4 } & Ponta & Meio & Base & Média \\
\cline { 2 - 4 } & \multicolumn{3}{c}{ Força (N) } \\
\hline RB765418 & 654,6 & 510,5 & 544,5 & 569,9 \\
RB72454 & 960,1 & 556,8 & 809,6 & 775,5 \\
SP791011 & 393,0 & 623,1 & 493,4 & 503,5 \\
SP711406 & 759,4 & 629,3 & 693,4 & 694,0 \\
SP701143 & 696,0 & 728,9 & $1.090,0$ & 838,3 \\
\hline Média & 693,8 & 609,7 & 726,4 \\
\hline
\end{tabular}

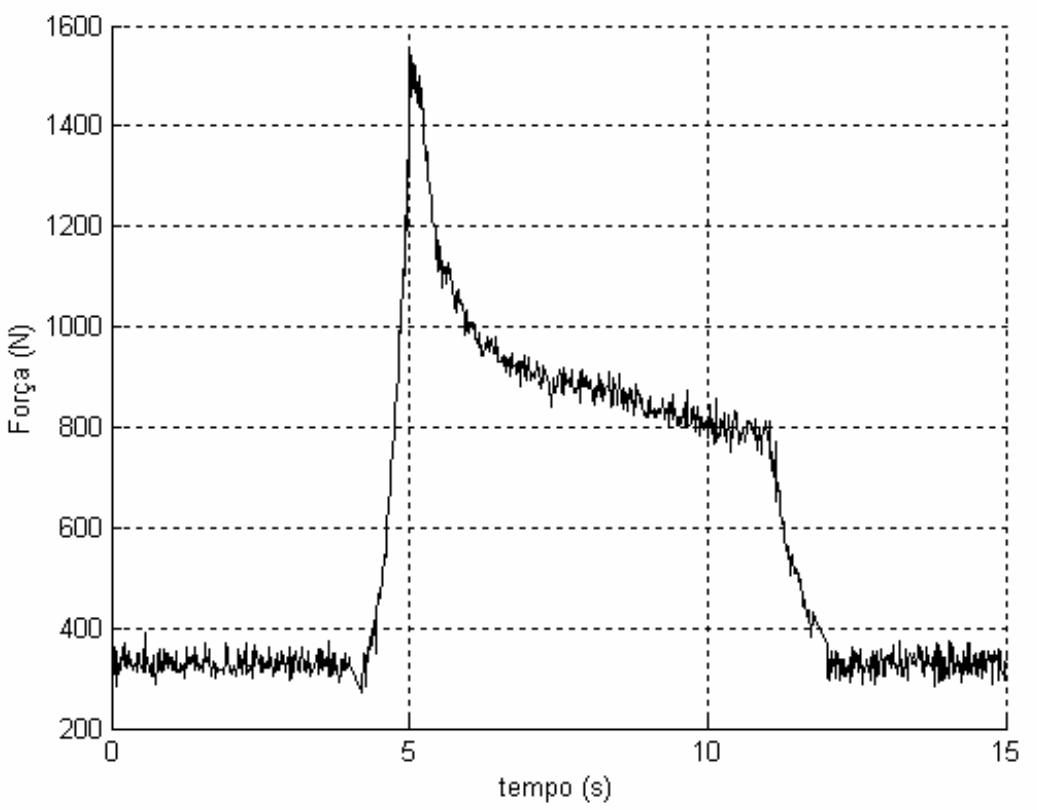

FIGURA 2. Força de compressão suportada pela cana-de-açúcar (N) em função do tempo (s).

Na Tabela 2, apresentam-se os valores médios obtidos nos ensaios de tração para remoção de folhas. Observa-se que não houve variação estatisticamente significativa a $5 \%$ da força de tração necessária para a remoção da palha com a variação da carga normal aplicada ou da variedade testada. Observou-se que, para uma força normal constante de $200 \mathrm{~N}$, obteve-se em média $71,15 \%$ de despalhe, sendo a força de tração média de 313,6 N. Para uma força normal de $250 \mathrm{~N}$, o despalhe foi de $81,54 \%$ e a força de tração de $316,5 \mathrm{~N}$. Essa carga normal, considerando a área de aplicação da carga, representa uma pressão de $0,8 \mathrm{MPa}$.

Para um total de 141 testes, para as diferentes forças normais aplicadas, obteve-se uma média de $73,05 \%$ de remoção da palha, com uma força de tração média de 315,1 N. Esses resultados consideram que as médias dessas forças são significativamente iguais para as variedades testadas, para as diferentes posições dos colmos e para as diferentes normais utilizadas. 
TABELA 2. Força necessária para a remoção das folhas $(\mathrm{N})$ de cinco variedades de cana-de-açúcar para diferente força normal $(\mathrm{N})$ aplicada.

\begin{tabular}{ccccc}
\hline \multirow{2}{*}{ Variedades } & \multicolumn{4}{c}{ Força Normal } \\
\cline { 2 - 5 } & Despalhe (\%) & Tração Média (N) & Despalhe (\%) & Tração Média (N) \\
\cline { 2 - 5 } RB765418 & 55,56 & 274,5 & 75,00 & 346,1 \\
RB72454 & 78,57 & 321,6 & 71,43 & 294,1 \\
SP791011 & 66,67 & 269,0 & 75,00 & 246,8 \\
SP711406 & 85,71 & 274,7 & 100,00 & 345,9 \\
SP701143 & 33,33 & 428,3 & 84,21 & 349,5 \\
\hline Média & 71,15 & 313,6 & 81,54 & 316,5 \\
\hline
\end{tabular}

\section{CONCLUSÕES}

A partir dos resultados obtidos, pode-se concluir que, como dado de projeto para dimensionar mecanismos que de alguma forma pressionam o colmo da cana-de-açúcar, a tensão normal máxima suportada pela cana-de-açúcar nas variedades testadas, sem que haja danos visíveis em sua estrutura, é de 4,9 MPa. Esse valor é independente da posição do colmo.

Da mesma forma, é possível separar a folha do colmo da cana-de-açúcar por atrito, aplicando uma tensão normal média de $0,8 \mathrm{MPa}$ e uma força de tração de aproximadamente $315 \mathrm{~N}$ para as variedades testadas, independentemente de sua posição relativa no colmo (basal, mediana e apical). Esse valor de carga normal está $83 \%$ abaixo do máximo valor suportado pela cana-de-açúcar, o que permite concluir que é possível desenvolver um mecanismo para remover a palha da cana-de-açúcar por atrito sem causar danos a sua estrutura.

\section{REFERÊNCIAS BIBLIOGRÁFICAS}

ABE, M.; KOJIMA, S.; MIYABE, Y. Studies on the development of a leaf-stripping system for a sugarcane. Bulletin of the Faculty of Agriculture, Kagoshima University, Kagoshima, n.29, p.217-24, 1979.

BROOK, R.J.; ARNOLD, G.C. Applied regression analysis and experimental design. New York : M. Dekker, 1985. 237 p.

CLAYTON, J.E. Field mechanization. Sugar y Azúcar, Baltimore, v.66, n.7, p.8-14, 1971.

CORTEZ, L.A.; MAGALHÃES; P.S.G., HAPP, J. Principais subprodutos da agroindústria canavieira e sua valorização. Revista Brasileira de Energia, v.2, n.2, p.111-46, 1992.

IEA - INSTITUTO DE ECONOMIA AGRÍCOLA. Anuário de 2001. Cana para a Indústria, São Paulo, v.13, n.1, 302 p., 2002.

MAGALHÃES, P.S.G.; BRAUNBECK, O.A. Colheita de cana-de-açúcar - atualidades e perspectivas. In: BALBUENA R H;. BENEZ, S. H.; JORAJURÍA, D. Ingeniería Rural y Mecanización Agrária en el ámbito Latinoamericano. La Plata: Editora de la Universidad Nacional de La Plata, 1998. v.1, p.262-73.

MIYABE, Y.; ABE, M. Fundamental studies on developing a leaf-stripping machine for sugarcane. I The pulling force needed for leaf detachment. Bulletin of the Faculty of Agriculture, Kagoshima University, Kagoshima, v.26, p.271-6, 1976. 
MIYABE, Y.; ABE, M. Fundamental studies on development of a leaf-stripping machine for sugarcane. II - The penetrating, bending, cutting and crushing resistance of a sugarcane stalk. Bulletin of the Faculty of Agriculture, Kagoshima University, Kagoshima, n.29, p.231-43, 1979.

MIYABE, Y.; ABE, M.; KOJIMA, S. Fundamental studies on the development of a leaf-stripping machine for sugarcane. III - The impact resistance of a sugarcane stalk. Bulletin of the Faculty of Agriculture, Kagoshima University, Kagoshima, n.29, p.245-8, 1979.

PATENTE: Brasil PI 203.875 de 11 de nov. de 1968 "Despalhador de Cana-de-açúcar com Bastões e/ ou Chicotes de Material Flexível”, Código de Recuperação: PMA/BR 004.

SHUKLA, L.N.; SINGH, I.; SANDHAR; N.S. Design development and testing of sugarcane cleaner. Agricultural Mechanization in Asia, Africa and Latin America, Tóquio, v.22, n.3, p.55-8, 1991.

SOUSA, M.B.F.; NÄÄS, I.A. Análise estatística dos resultados de avaliação dos níveis de amônia em granjas comerciais de frangos de corte. 2003. 42 f. Relatório final (Iniciação científica) - Faculdade de Engenharia Agrícola, UNICAMP, Campinas, 2003.

SRIVASTAVA, A.C. An investigation of sugarcane detrashing. St. Joseph: American Society of Agricultural Engineers, 1987. 16 p. (Paper n. 87-5054)

SRIVASTAVA, A.C.; SINGH, S.K. Development of a power-driven sugarcane detrasher. Agricultural Mechanization in Asia, Africa and Latin America, Tóquio, v.21, n.2, p.49-52, 1990. 